\title{
Adult, isolated respiratory chain complex IV deficiency with minimal manifestations
}

\author{
Josef Finsterer ${ }^{1}$, Gabor G. Kovacs ${ }^{2}$, Helmut Rauschka ${ }^{3}$, Uwe Ahting ${ }^{4}$ \\ ${ }^{1}$ Krankenanstalt Rudolfstiftung, Vienna, Austria, ${ }^{2}$ Institute of Neurology, Medical University of Vienna, Vienna, Austria, ${ }^{3}$ Neurological \\ Department, SMZO, Vienna, Austria, ${ }^{4}$ Institute of Clinical Chemistry, Munich, Germany
}

\begin{abstract}
Objectives: Isolated complex IV (cytochrome c oxidase) deficiency is one of the most frequent respiratory chain defects in mitochondrial disorders (MIDs) and usually occurs together with severe pediatric or rarely adult multisystem disease. Here we report an adult with isolated complex IV deficiency with unusually mild clinical manifestations. Case report: A 50-year-old man had developed generalized muscle aches and occasional twitching and stiffness of the musculature since age 48 years. He had a previous history of diabetes, acute hearing loss, hyperlipidemia, hyperuricemia, arterial hypertension, polyarthrosis, hypogonadism, and hypothyroidism. The family history was positive for diabetes (mother), CK elevation (brother), myalgias (brother), and proximal weakness of the upper limbs (mother). Work-up revealed hypoacusis, postural tremor and reduced tendon reflexes, recurrent mild hyper-CK-emia, neurogenic needle electromyography, and a muscle biopsy with mild non-specific changes. Biochemical investigations of the muscle homogenate revealed an isolated complex IV defect and reduced amounts of coenzyme Q (CoQ). He profited from $\mathrm{CoQ}$ supplementation, low-carbohydrate diet, and gluten-free diet.

Conclusions: Isolated complex IV deficiency may present with only mild muscular, endocrine, or cardiac manifestations in adults. Coenzyme $Q$ supplementation, low-carbohydrate diet, and gluten-free diet may have a beneficial effect at least on some of the manifestations.
\end{abstract}

Key words: mitochondrial, myopathy, metabolic, multisystem, complex IV, cytochrome c oxidase, muscle biopsy, creatine kinase.

\section{Introduction}

Primary mitochondrial disorders (MIDs) are due to mutations in mitochondrial DNA (mtDNA) or nuclear DNA (nDNA)-located genes that encode subunits of respiratory chain complexes, assembly factors (ancillary proteins), proteins involved in mtDNA maintenance (intergenomic signaling), in the mitochondrial protein synthesis machinery, in coenzyme $\mathrm{Q}$ generation, in the mitochondrial transport machinery, or in apoptosis [7,8]. These mutations may occur together with reduced activity of single or multiple respiratory chain complexes in biochemical investigations $[7,8]$. Isolated complex IV (cytochrome c oxidase) deficiency is one of the most frequent respiratory chain defects in MIDs and usually occurs together with severe pediatric or rarely adult multisystem disease [20]. Here we report an adult with 
isolated complex IV deficiency with unusually mild clinical manifestations.

\section{Case report}

The patient is a 50-year-old Caucasian man, height $172 \mathrm{~cm}$, weight $84 \mathrm{~kg}$, with a history of spontaneous, permanent aching predominantly of the thighs and less intense aching of the lower legs, the neck, and the shoulder girdle muscles since the age of 48 years. Muscle aching could be slightly reduced by initiation of exercise but was markedly intensified after exercise during several days. He reported "heavy legs" after running and occasional twitching and stiffness of the musculature. His previous history was noteworthy for diabetes, acute hearing loss, hyperlipidemia, hyperuricemia, arterial hypertension, which had been well controlled with appropriate medication for 3 years, polyarthrosis, hypogonadism, and hypothyroidism since age 38 years. He also reported a mushy stool for years with slight improvement after changing to a gluten-free diet. The family history was positive for diabetes (mother), CK elevation (brother), myalgias (brother), and proximal weakness of the upper limbs (mother). Clinical neurologic examination at age 50 years revealed slight hypoacusis, mild postural tremor and markedly reduced tendon reflexes. His muscles were generally sore.

Work-up revealed recurrently elevated creatine kinase (CK) values with a maximum value of $1200 \mathrm{U} / \mathrm{l}$ $(n,<190 \mathrm{U} / \mathrm{l})$ but normal values during several months prior to the last visit in $2 / 2014$. Serum lactate and the forearm ischemic test were normal. Nerve conduction studies of the right femoral nerve, the median and peroneal nerves bilaterally, the left sural nerve and the sensory fibers of the median nerves bilaterally, were all normal. Needle electromyography of two muscles in 6/2011 was normal. Needle electromyography of the right quadriceps femoris muscle in 10/2013 was, in contrast, neurogenic, revealing extensive fibrillations and fasciculations at all recording points, enlarged motor units, and a clear interference pattern. Muscle biopsy from the left lateral vastus muscle in 4/2012 showed two "Ringbinden" (Fig. 1A), one COX-negative fiber (Fig. 1B), and slight type 2 fiber predominance. Ultrastructural examination revealed fibers with subsarcolemmal accumulation of mitochondria and lipid droplets (Fig. 1C), but there was a lack of paracrystalline inclusions or other structural alterations.
Biochemical investigations of the muscle homogenate revealed an isolated complex IV defect and reduced amounts of CoQ (Table I). $\mathrm{HbA}_{1 \mathrm{c}}$ was 6.5 $(n,<6.0)$. Echocardiography revealed only mild concentric hypertrophy. Ultrasound of the upper abdomen revealed steatosis hepatis exclusively. Magnetic resonance imagine of the cervical spine was normal. His last medication comprised amlodipine (10 mg/d), L-thyroxine $(50 \mu \mathrm{g} / \mathrm{d}), \mathrm{CoQ}(300 \mathrm{mg} / \mathrm{d})$, and metformin $(1000 \mathrm{mg} / \mathrm{d})$. He could accomplish his daily job as an engineer with only progressively stiff neck muscles with increasing duration of his working hours.

\section{Discussion}

Isolated complex IV deficiency is one of the most common biochemical abnormalities in MIDs $[4,19]$. Isolated complex IV deficiency is clinically and genetically extremely heterogeneous (Table II). Clinical manifestations may range from fatal encephalopathy [19], Leigh syndrome (a severe neurodegenerative disorder with characteristic bilateral lesions in the basal ganglia and the brainstem [20]), or epilepsy to myopathy, rhabdomyolysis, or hypertrophic cardiomyopathy (Table II). Genetically, isolated complex IV deficiency may be due to mtDNA mutations or nDNA mutations. mtDNA-located genes associated with isolated complex IV deficiency include genes encoding tRNAs or subunits of complex IV (COX-I, COX-II, COX-III) (Table II). nDNA-located genes associated with isolated complex IV deficiency include an even larger number of genes (Table II). Genes most commonly mutated in isolated complex IV deficiency include SURF1 [20] and SCO2 [3,31].

The reason why such a heterogeneous genetic background leads to the same biochemical defect remains elusive, but it can be speculated that the so far reported genes involved in isolated complex IV deficiency contribute to the composition, assembly, or maintenance of complex IV. Why tRNA mutations cause complex IV deficiency also remains elusive, but these mutations may specifically impair the translation of components of complex IV. Whether hypoacusis, diabetes, arterial hypertension, hyperlipidemia, polyarthralgia, hyperuricemia, hypothyroidism, and hypogonadism have to be regarded as manifestations of the mitochondrial defect remains speculative but previous reports suggest that these manifestations can be occasionally found in patients with MIDs [9]. Since serum CoQ levels were markedly 

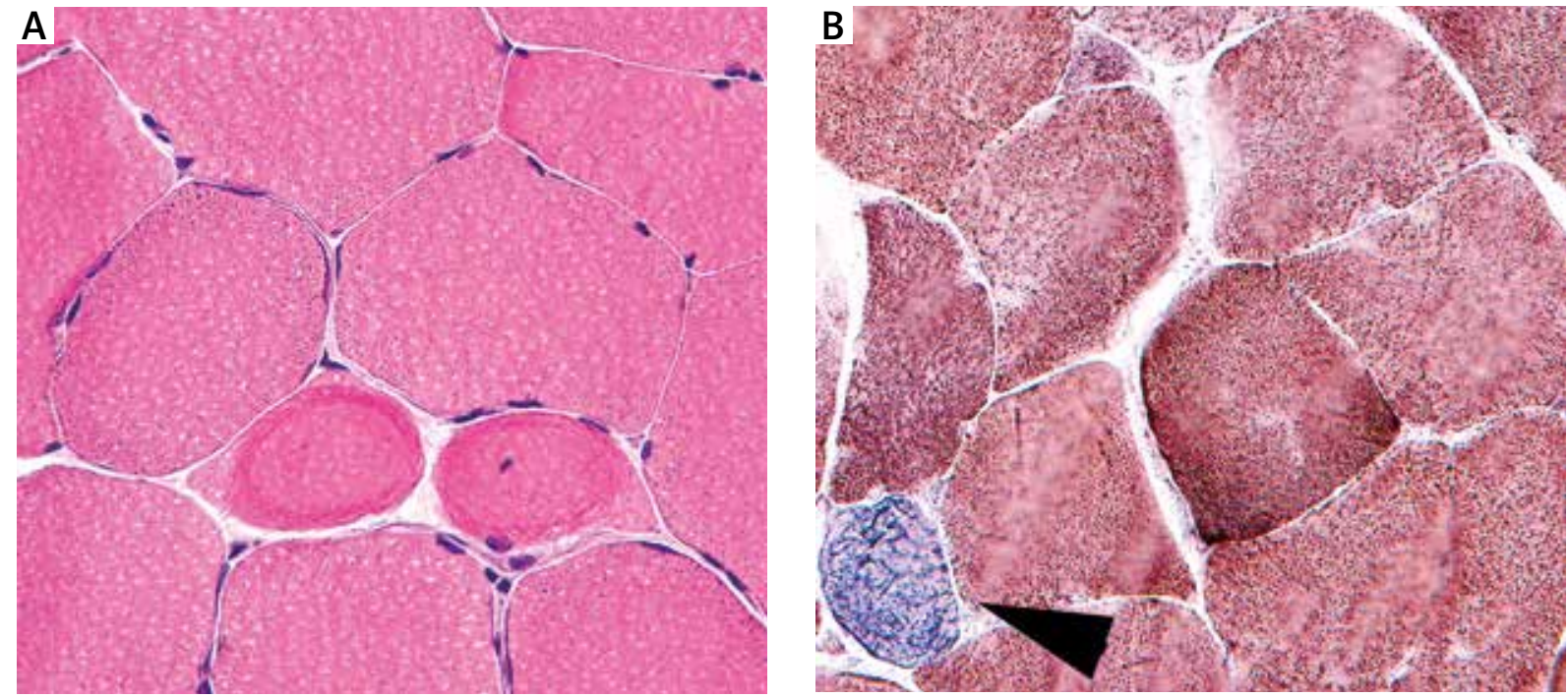

Fig. 1. Hematoxylin and eosin staining of the muscle shows two "Ringbinden" (A). Enzyme histochemistry for COX/SDH reveals a single COX negative fiber (arrowhead) (B). Electron microscopy shows lipid droplets (arrowhead) and subsarcolemmal accumulation of mitochondria (arrow) without paracrystalline inclusions (C).

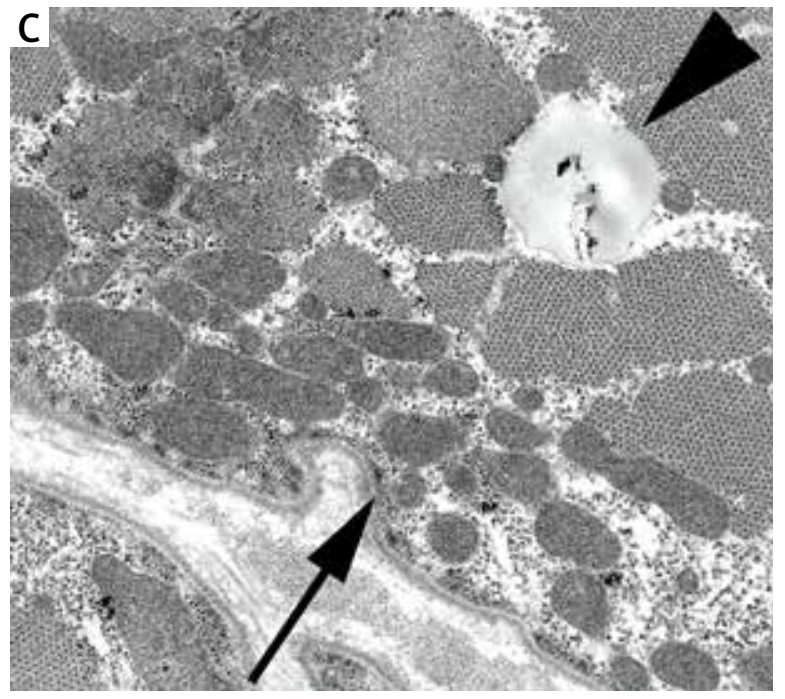

Table I. Results of biochemical investigations of muscle homogenate in the presented patient

\begin{tabular}{|lcc|}
\hline Enzyme activity & Reference limit & Result \\
\hline Related to non-collagen protein & $15.8-42.8 \mathrm{U} / \mathrm{gNCP}$ & 15.6 \\
\hline Complex I (NADH-CoQ oxidoreductase) & $6.0-25.0 \mathrm{U} / \mathrm{gNCP}$ & 9.1 \\
\hline Complex II/III (succinate cytochrome c oxidoreductase) & $112-351 \mathrm{U} / \mathrm{gNCP}$ & 46.4 \\
\hline Complex IV (cytochrome c oxidase) & $160-1200 \mathrm{mmol} / \mathrm{gNCP}$ & 111.6 \\
\hline Coenzyme Q & & 0.26 \\
\hline Related to citrate synthetase & $0.17-0.56 \mathrm{U} / \mathrm{U}$ CS & 0.15 \\
\hline Complex I (NADH-CoQ oxidoreductase) & $0.08-0.45 \mathrm{U} / \mathrm{U}$ CS & 0.76 \\
\hline Complex II/III (succinate cytochrome c oxidoreductase) & $1.1-5.0 \mathrm{U} / \mathrm{U}$ CS & 1.8 \\
\hline Complex IV (cytochrome c oxidase) & $2.7-7.0 \mathrm{mmol} / \mathrm{U} \mathrm{CS}$ & \\
\hline
\end{tabular}

NCP-non-collagen protein 
Table II. Clinical manifestations of and mutated genes in isolated complex IV deficiency

\begin{tabular}{|c|c|c|}
\hline & $\begin{array}{l}\text { Mutated } \\
\text { gene }\end{array}$ & Reference \\
\hline \multicolumn{3}{|l|}{ Clinical presentation mtDNA } \\
\hline Encephalomyopathy & tRNA(Arg) & [24] \\
\hline Leigh syndrome & tRNA(Leu) & {$[3]$} \\
\hline Leigh syndrome $(8344,8363)$ & tRNA(Lys) & [3] \\
\hline Deafness, epilepsy, ataxia & tRNA(Ser) & [29] \\
\hline Stroke, epilepsy, lactic acidosis & $\operatorname{cox}-1$ & {$[16]$} \\
\hline MELAS, encephalomyopathy & $\operatorname{cox}-11$ & {$[15,25]$} \\
\hline Myopathy & COX-III & {$[15]$} \\
\hline Myoglobinuria & COX-III & {$[14]$} \\
\hline Encephalomyopathy & COX-III & {$[13,18]$} \\
\hline \multicolumn{3}{|l|}{ nDNA } \\
\hline Leigh syndrome & SURF1 & {$[3,6,20]$} \\
\hline Fatal encephalopathy & SCO1 & {$[19]$} \\
\hline Cardioencephalomyopathy & $\mathrm{SCO} 2$ & {$[3,10,31]$} \\
\hline Werdnig-Hoffmann disease & $\mathrm{SCO} 2$ & {$[27]$} \\
\hline $\begin{array}{l}\text { Leigh syndrome, anemia, } \\
\text { deafness }\end{array}$ & COX10 & {$[1,6]$} \\
\hline Leigh syndrome & COX15 & {$[5]$} \\
\hline Hypertrophic cardiomyopathy & COX15 & {$[2]$} \\
\hline Epilepsy & C19orf79 & {$[20]$} \\
\hline COX-deficiency & NDUFA4 & [23] \\
\hline Megaconial myopathy & CHKB & {$[12]$} \\
\hline Cognition $\downarrow$, dystonia, vision $\downarrow$ & TACO1 & [28] \\
\hline Encephalomyopathy & FASTKD2 & {$[11]$} \\
\hline \multicolumn{3}{|l|}{ No mutations described } \\
\hline Isolated myopathy & n.s. & {$[17]$} \\
\hline Adult Leigh syndrome & n.s. & {$[22]$} \\
\hline Hypertrophic cardiomyopathy & n.s. & [30] \\
\hline Encephalo-hepatopathy & n.s. & {$[19,26]$} \\
\hline Hypertrophic cardiomyopathy & n.s. & {$[19,26]$} \\
\hline MERRF & n.s. & {$[21]$} \\
\hline Myalgia, diabetes, hypoacusis & n.s. & $\begin{array}{c}\text { [Current } \\
\text { case] }\end{array}$ \\
\hline
\end{tabular}

reduced, a substitution therapy with CoQ $300 \mathrm{mg} / \mathrm{d}$ was begun, with some beneficial effect. Low carbohydrate diet enhanced this effect.

This case shows that isolated complex IV deficiency may present with only mild muscular, endocrine, or cardiac manifestations. Coenzyme Q supplementation, low-carbohydrate diet, and gluten-free diet may have a beneficial effect at least on some of the manifestations.

\section{Disclosure}

The authors report no conflict of interest.

\section{References}

1. Antonicka H, Leary SC, Guercin GH, Agar JN, Horvath R, Kennaway NG, Harding CO, Jaksch M, Shoubridge EA. Mutations in COX10 result in a defect in mitochondrial heme $A$ biosynthesis and account for multiple, early-onset clinical phenotypes associated with isolated COX deficiency. Hum Mol Genet 2003; 12: 2693-2702.

2. Antonicka H, Mattman A, Carlson CG, Glerum DM, Hoffbuhr KC, Leary SC, Kennaway NG, Shoubridge EA. Mutations in COX15 produce a defect in the mitochondrial heme biosynthetic pathway, causing early-onset fatal hypertrophic cardiomyopathy. Am J Hum Genet 2003; 72: 101-114.

3. Böhm M, Pronicka E, Karczmarewicz E, Pronicki M, Piekutowska-Abramczuk D, Sykut-Cegielska J, Mierzewska H, Hansikova H, Vesela K, Tesarova M, Houstkova H, Houstek J, Zeman J. Retrospective, multicentric study of 180 children with cytochrome C oxidase deficiency. Pediatr Res 2006; 59: 21-26.

4. Bourens M, Boulet A, Leary SC, Barrientos A. Human COX20 cooperates with SCO1 and SCO2 to mature COX2 and promote the assembly of cytochrome c oxidase. Hum Mol Genet 2014; 23: 2901-2913.

5. Bugiani M, Tiranti V, Farina L, Uziel G, Zeviani M. Novel mutations in COX15 in a long surviving Leigh syndrome patient with cytochrome c oxidase deficiency. J Med Genet 2005; 42: e28.

6. Coenen MJ, Smeitink JA, Pots JM, van Kaauwen E, Trijbels FJ, Hol FA, van den Heuvel LP. Sequence analysis of the structural nuclear encoded subunits and assembly genes of cytochrome $c$ oxidase in a cohort of 10 isolated complex IV-deficient patients revealed five mutations. J Child Neurol 2006; 21: 508-511.

7. DiMauro S, Schon EA, Carelli V, Hirano M. The clinical maze of mitochondrial neurology. Nat Rev Neurol 2013; 9: 429-444.

8. Finsterer J. Inherited mitochondrial disorders. Adv Exp Med Biol 2012; 942: 187-213.

9. Finsterer J, Jarius C, Eichberger H. Phenotype variability in 130 adult patients with respiratory chain disorders. J Inherit Metab Dis 2001; 24: 560-576.

10. Foltopoulou PF, Tsiftsoglou AS, Bonovolias ID, Ingendoh AT, Papadopoulou LC. Intracellular delivery of full length recombinant human mitochondrial L-SCO2 protein into the mitochondria of permanent cell lines and SCO2 deficient patient's primary cells. Biochim Biophys Acta 2010; 1802: 497-508. 
11. Ghezzi D, Saada A, D’Adamo P, Fernandez-Vizarra E, Gasparini P, Tiranti V, Elpeleg O, Zeviani M. FASTKD2 nonsense mutation in an infantile mitochondrial encephalomyopathy associated with cytochrome c oxidase deficiency. Am J Hum Genet 2008; 83: 415-423.

12. Gutiérrez Ríos P, Kalra AA, Wilson JD, Tanji K, Akman HO, Area Gómez E, Schon EA, DiMauro S. Congenital megaconial myopathy due to a novel defect in the choline kinase Beta gene. Arch Neurol 2012; 69: 657-661.

13. Hanna MG, Nelson IP, Rahman S, Lane RJ, Land J, Heales S, Cooper MJ, Schapira AH, Morgan-Hughes JA, Wood NW. Cytochrome $c$ oxidase deficiency associated with the first stopcodon point mutation in human mtDNA. Am J Hum Genet 1998; 63: 29-36.

14. Hoffbuhr KC, Davidson E, Filiano BA, Davidson M, Kennaway NG, King MP. A pathogenic 15-base pair deletion in mitochondrial DNA-encoded cytochrome c oxidase subunit III results in the absence of functional cytochrome c oxidase. J Biol Chem 2000; 275: 13994-14003.

15. Horváth R, Schoser BG, Müller-Höcker J, Völpel M, Jaksch M, Lochmüller $\mathrm{H}$. Mutations in mtDNA-encoded cytochrome $\mathrm{C}$ oxidase subunit genes causing isolated myopathy or severe encephalomyopathy. Neuromuscul Disord 2005; 15: 851-857.

16. Jaksch M, Hofmann S, Kleinle S, Liechti-Gallati S, Pongratz DE, Müller-Höcker J, Jedele KB, Meitinger T, Gerbitz KD. A systematic mutation screen of 10 nuclear and 25 mitochondrial candidate genes in 21 patients with cytochrome coxidase (COX) deficiency shows tRNA(Ser)(UCN) mutations in a subgroup with syndromal encephalopathy. J Med Genet 1998; 35: 895-900.

17. Karadag A, Avci Z, Catal F, Odemis E. Cytochrome c oxidase deficiency in a child with isolated myopathy. Fetal Pediatr Pathol 2005; 24: 149-153.

18. Keightley JA, Hoffbuhr KC, Burton MD, Salas VM, Johnston WS, Penn AM, Buist NR, Kennaway NG. A microdeletion in cytochrome c oxidase (COX) subunit III associated with COX deficiency and recurrent myoglobinuria. Nat Genet 1996; 12: 410-416.

19. Leary SC, Antonicka H, Sasarman F, Weraarpachai W, Cobine PA, Pan M, Brown GK, Brown R, Majewski J, Ha KC, Rahman S, Shoubridge EA. Novel mutations in SCO1 as a cause of fatal infantile encephalopathy and lactic acidosis. Hum Mutat 2013; 34 1366-1370

20. Lim SC, Smith KR, Stroud DA, Compton AG, Tucker EJ, Dasvarma A, Gandolfo LC, Marum JE, McKenzie M, Peters HL, Mowat D, Procopis PG, Wilcken B, Christodoulou J, Brown GK, Ryan MT, Bahlo M, Thorburn DR. A founder mutation in PET100 causes isolated complex iv deficiency in Lebanese individuals with Leigh syndrome. Am J Hum Genet 2014; 94: 209-222.

21. Lombes A, Mendell JR, Nakase H, Barohn RJ, Bonilla E, Zeviani M, Yates AJ, Omerza J, Gales TL, Nakahara K, et al. Myoclonic epilepsy and ragged-red fibers with cytochrome oxidase deficiency: neuropathology, biochemistry, and molecular genetics. Ann Neurol 1989; 26: 20-33.

22. Marsac C, Degoul F, Bonne G, Romero N, Nelson I, Fardeau M, François D, Ponsot G, Harpey JP, Eymard B, et al. Mitochondrial function and mitochondrial DNA in a series of 64 patients suspected of having mitochondrial myopathy. Rev Neurol (Paris) 1991; 147: 462-466.
23. Pitceathly RD, Rahman S, Wedatilake Y, Polke JM, Cirak S, Foley AR, Sailer A, Hurles ME, Stalker J, Hargreaves I, Woodward CE, Sweeney MG, Muntoni F, Houlden H, Taanman JW, Hanna MG; UK10K Consortium. NDUFA4 mutations underlie dysfunction of a cytochrome c oxidase subunit linked to human neurological disease. Cell Rep 2013; 3: 1795-1805.

24. Roos S, Darin N, Kollberg G, Andersson Grönlund M, Tulinius M, Holme E, Moslemi AR, Oldfors A. A novel mitochondrial tRNA Arg mutation resulting in an anticodon swap in a patient with mitochondrial encephalomyopathy. Eur J Hum Genet 2013; 21: 571-573.

25. Rossmanith W, Freilinger M, Roka J, Raffelsberger T, MoserTheir K, Prayer D, Bernert G, Bittner R. Isolated cytochrome c oxidase deficiency as a cause of MELAS. BMJ Case Rep 2009; 2009.

26. Sacconi S, Salviati L, Sue CM, Shanske S, Davidson MM, Bonilla E, Naini AB, De Vivo DC, DiMauro S. Mutation screening in patients with isolated cytochrome c oxidase deficiency. Pediatr Res 2003; 53: 224-230.

27. Salviati L, Sacconi S, Rasalan MM, Kronn DF, Braun A, Canoll P, Davidson M, Shanske S, Bonilla E, Hays AP, Schon EA, DiMauro S. Cytochrome c oxidase deficiency due to a novel $\mathrm{SCO} 2$ mutation mimics Werdnig-Hoffmann disease. Arch Neurol 2002; 59: 862-865.

28. Seeger J, Schrank B, Pyle A, Stucka R, Lörcher U, Müller-Ziermann S, Abicht A, Czermin B, Holinski-Feder E, Lochmüller H, Horvath R. Clinical and neuropathological findings in patients with TACO1 mutations. Neuromuscul Disord 2010; 20: 720-724.

29. Tam EW, Feigenbaum A, Addis JB, Blaser S, Mackay N, Al-Dosary M, Taylor RW, Ackerley C, Cameron JM, Robinson BH. A novel mitochondrial DNA mutation in COX1 leads to strokes, seizures, and lactic acidosis. Neuropediatrics 2008; 39: 328-334.

30. Venditti CP, Harris MC, Huff D, Peterside I, Munson D, Weber HS, Rome J, Kaye EM, Shanske S, Sacconi S, Tay S, DiMauro S, Berry GT. Congenital cardiomyopathy and pulmonary hypertension: another fatal variant of cytochrome-c oxidase deficiency. J Inherit Metab Dis 2004; 27: 735-739.

31. Vesela K, Hansikova H, Tesarova M, Martasek P, Elleder M, Houstek J, Zeman J. Clinical, biochemical and molecular analyses of six patients with isolated cytochrome $c$ oxidase deficiency due to mutations in the SCO2 gene. Acta Paediatr 2004; 93: 1312-1317. 